\title{
Mouth Washes - A Paradigm Shift from Chlorhexidine Gluconate to Essential Oil Mouthwash A Meta Analysis
}

Dr.Sajid Hussain,B.Sc.,B.D.S,M.D.S ( $\sim$ sajid2000@gmail.com )

Sree Balaji Dental College And Hospital

Short Report

Keywords: Chlorhexidine, essential oils, meta-analysis, plaque

Posted Date: August 13th, 2021

DOl: https://doi.org/10.21203/rs.3.rs-800244/v1

License: (c) (1) This work is licensed under a Creative Commons Attribution 4.0 International License.

Read Full License 


\section{Abstract}

Background: The purpose of this review is to systematically evaluate the effects of an essential-oil mouthwash compared to a chlorhexidine mouthwash with respect to plaque and parameters of gingival inflammation.

Methods: PubMed databases were searched for studies up to and including may 2015. A comprehensive search was designed and the articles were independently screened. Articles that evaluated the effects of the essential oil mouthwash compared to chlorhexidine mouthwash were included. A meta-analysis was performed, and weighted mean differences were calculated.

Results: A total of 17 unique articles were found, of which 11 articles met the eligibility criteria. A metaanalysis of long-term studies (duration $>3$ months) showed that the essential oil mouthwash provided significantly better effects regarding prophylactic plaque control than chlorhexidine

Conclusion: In long-term use, the standardized formulation of essential oil mouthwash is more reliable than chlorhexidine mouthwash.

\section{Introduction:}

Man in the recent times has achieved a giant leap in the field of dentistry. With the increase in the knowledge and attitude of the newer technological enhanced patients, the concept of treatment is now increasingly been replaced by prevention ${ }^{1}$. The paradigm is now been shifted from disability limitation to treatment of diseases. Gingivitis is not an exemption here. This reversible form of the disease has seen in the last two decades shows a paradigm shift from treatment to prevention. With improvement at genetic and molecular levels, understanding the disease cause and disease progression has now become easier. With knowledge empowerment in this sector, a lot has been achieved in the treatment and prevention sector. It has been always the mindset of a dental patient that prevention is always better than cure as it is rightly said an ounce of prevention is better than a pound of cure. In the field of dentistry especially with regards to dentistry rings the bell of chlorhexidine in the mind of the dentist. Gingivitis and various forms of periodontal disease have always been attributed to the complex formation of plaque adherence, accumulation, initiation and progression of disease on the biofilm. Enriched information is now increasingly available on the complex mechanism involved in biofilm and plaque formation ${ }^{4}$. Listerine the first ever formed essential oil antiseptic was given to the world by Joseph Lawrence Lister in the year $1879^{1}$. Though this has been introduced almost a millennium to chlorhexidine, the usage of essential oil mouthwashes has been limited for the treatment of halitosis in the dental field. With the antiseptic chlorhexidine discovery in the 1940's when it was first introduced to the world by Imperial Chemical Industries in England ${ }^{1}$. 1950's saw chlorhexidine as a popular general antiseptic in comparison with essential oil mouthwash wash ${ }^{2}$. The ability to inhibit oral plaque by chlorhexidine was first observed by Schroeder in $1969^{3}$ and it was evidenced in a more scientific manner by Loe and Schiott $1972^{4}$. From time immemorial plaque buildup was challenged indispensable by chlorhexidine gluconate with 
practically no replacement or alternate strategies available for it. Since then a war is waged as to which is mightier - chlorhexidine or essential oil mouthwash!

Chlorhexidine $(\mathrm{CHX})$ is a broad-spectrum antimicrobial agent that destroys the cell membrane by precipitation and coagulation of the cytoplasmic proteins of the microbial flora. Chlorhexidine mouth rinses are available in the form of $0.2 \%$ and $0.12 \%$ and it has been

show that their efficacy is similar at similar doses ${ }^{5}$. Essential oil mouthwash also inhibits plaque formation by destroying the cell membrane in addition to interference with the inflammatory process. The prophylactic usage of gold standard chlorhexidine and essential oil mouthwash remains a debatable topic. With the usage of antibiotics, chlorhexidine has been scrutinized in the recent times due to complication of resistance and increased staining properties, the usage of chlorhexidine is now warranted. Reports by both the American and British professional societies have now given an insight so as to the usage of prophylactic usage of mouth rinses. Chlorhexidine is still considered as the gold standard for its antimicrobial action but due to increased plaque formation, staining capacity and resistance may now limit its continued use ${ }^{1}$. These

Arguments bring us to light about the fact that -chlorhexidine can still be considered as a gold standard for prophylactic prevention or the time has come for its reconsideration.

\section{Materials And Methods:}

For this Meta analysis, studies that were randomized clinical trials (RCTs) or controlled trials in healthy human subjects comparing the effects of chlorhexidine gluconate and essential oil mouthwashes on plaque levels for at least 3 months were included. There was no restriction on the amount or percentage of the mouthwashes. The plaque levels in all the included study were taken with one of the following indices: Plaque Index by Silness \& Löe $(1964)^{6}$, Plaque-Index by Quigley \& Hein (1970) ${ }^{7}$ and its modification by Turesky S, Gilmore N D \& Glickman (1970) ${ }^{8}$.

The search was done from the pub med central listed studies from 2003 to 2014 with the use of keywords with Boolean operators during the month of May 2015 (chlorhexidine, essential oil, mouth wash, randomized control trials). 17 unique articles were obtained from electronic database search (pub med central). Only 11 studies were pooled in for the Meta analysis (table 1). The other studies were not included as they were either in vitro experiments, experiments done on laboratory animals, and a few studies had used microbial techniques with gingival parameters. The fixed effects model was used for analysis when compared to the random effects model as the data was more heterogeneous. Chi square was used to compute heterogeneity based on the standard deviation and confidence levels of all the selected studies.

\section{Table I - various studies used for Meta Analysis}




\begin{tabular}{|c|c|c|c|c|c|c|c|c|c|}
\hline \multirow{2}{*}{$\begin{array}{l}\text { Sl. } \\
\text { No }\end{array}$} & \multirow{2}{*}{$\begin{array}{l}\text { Author } \\
\text { name }\end{array}$} & \multicolumn{3}{|c|}{ Chlorhexidine extracts } & \multicolumn{3}{|c|}{ Herbal extracts } & \multirow[t]{2}{*}{ Weight } & \multirow{2}{*}{$\begin{array}{l}\text { Mean } \\
\text { Difference } \\
\text { IV Fixed } \\
95 \% \text { CI }\end{array}$} \\
\hline & & $\begin{array}{l}\text { Mea } \\
n\end{array}$ & SD & $\begin{array}{l}\text { Total No } \\
\text { of study } \\
\text { subjects }\end{array}$ & Mean & SD & $\begin{array}{l}\text { Total } \\
\text { No } \\
\text { of study } \\
\text { subject s }\end{array}$ & & \\
\hline 1 & $\begin{array}{l}\text { Brecx M } \\
\text { et } \mathrm{al}^{9}\end{array}$ & 0.5 & $\begin{array}{l}0.0 \\
4\end{array}$ & 25 & 0.25 & $\begin{array}{l}0.0 \\
4\end{array}$ & 25 & $\begin{array}{l}14.30 \\
\%\end{array}$ & $\begin{array}{l}0.25 \\
(0.23, \\
0.27)\end{array}$ \\
\hline 2 & $\begin{array}{l}\text { Charles C } \\
\mathrm{H} \text { et } \\
\mathrm{al}_{10}\end{array}$ & 1.77 & $\begin{array}{l}0.0 \\
7\end{array}$ & 36 & 1.71 & $\begin{array}{l}0.0 \\
8\end{array}$ & 36 & $\begin{array}{l}14.20 \\
\%\end{array}$ & $\begin{array}{l}0.06 \\
(0.03,0.09 \\
)\end{array}$ \\
\hline 3 & \begin{tabular}{c}
\multicolumn{2}{c}{ Claydon } \\
$\mathrm{N}$ et \\
$\mathrm{al}_{11}$
\end{tabular} & 6.6 & $\begin{array}{l}3.0 \\
8\end{array}$ & 21 & 0.38 & $\begin{array}{l}0.2 \\
8\end{array}$ & 21 & $1.40 \%$ & $\begin{array}{l}6.22 \\
(4.90, \\
7.54)\end{array}$ \\
\hline 4 & $\begin{array}{l}\text { Kouzmina } \\
\text { E et } \\
\mathrm{al}_{12}\end{array}$ & 1.3 & $\begin{array}{l}0.0 \\
9\end{array}$ & 31 & 0.97 & $\begin{array}{l}0.0 \\
9\end{array}$ & 31 & $\begin{array}{l}14.20 \\
\%\end{array}$ & $\begin{array}{l}0.33 \\
(0.29, \\
0.37)\end{array}$ \\
\hline
\end{tabular}




\begin{tabular}{|c|c|c|c|c|c|c|c|c|c|}
\hline 5 & Botelho, M. $\mathrm{A}^{13}$ & 1.7 & \begin{tabular}{l|}
1.9 \\
1
\end{tabular} & 28 & \begin{tabular}{|l|}
1.75 \\
\end{tabular} & $\begin{array}{l}1.9 \\
2\end{array}$ & 28 & $2.20 \%$ & $\begin{array}{l}-0.05 \\
(-1.06 \\
0.96)\end{array}$ \\
\hline 6 & Addy, $\mathrm{M}$ et $\mathrm{al}^{14}$ & 0.7 & $\begin{array}{l}0.2 \\
1\end{array}$ & 15 & 1.35 & $\begin{array}{l}0.3 \\
9\end{array}$ & 15 & $\begin{array}{l}11.30 \\
\%\end{array}$ & $\begin{array}{l}-0.65 \\
(-0.87 \\
-0.43)\end{array}$ \\
\hline 7 & $\begin{array}{l}\text { Maruniak, J et } \\
\text { al }_{15}\end{array}$ & 2.87 & $\begin{array}{l}1.0 \\
9\end{array}$ & 24 & 2.2 & 1.6 & 24 & $3.40 \%$ & $\begin{array}{l}0.67 \\
(-0.10,1.4 \\
4)\end{array}$ \\
\hline 8 & Sharma $\mathrm{N}$ et $\mathrm{al}^{16}$ & 2.37 & $\begin{array}{l}0.3 \\
8\end{array}$ & 79 & \begin{tabular}{|l|}
1.13 \\
\end{tabular} & $\begin{array}{l}0.6 \\
6\end{array}$ & 79 & $\begin{array}{l}12.50 \\
\%\end{array}$ & $\begin{array}{l}1.24 \\
(1.07,1.41 \\
)\end{array}$ \\
\hline 9 & $\begin{array}{l}\text { Shetty Prashant } \\
\text { R et } \mathrm{al}^{17}\end{array}$ & 2.23 & 0.3 & 10 & \begin{tabular}{|l|}
2.09 \\
\end{tabular} & $\begin{array}{l}0.1 \\
5\end{array}$ & 10 & $\begin{array}{l}11.60 \\
\%\end{array}$ & $\begin{array}{l}0.14 \\
(-0.07 \\
0.35)\end{array}$ \\
\hline 10 & $\begin{array}{lll}\text { Ramberg } & \mathrm{P} & \text { et } \\
\mathrm{al}_{18} & & \end{array}$ & 0.88 & $\begin{array}{l}0.1 \\
6\end{array}$ & 10 & \begin{tabular}{|l|}
0.53 \\
\end{tabular} & $\begin{array}{l}0.1 \\
7\end{array}$ & 10 & $\begin{array}{l}12.90 \\
\%\end{array}$ & $\begin{array}{l}0.35 \\
(0.21 \\
0.49)\end{array}$ \\
\hline 11 & Sekino et $\mathrm{al}^{19}$ & 2.08 & $\begin{array}{l}1.1 \\
2\end{array}$ & 7 & 1.36 & $\begin{array}{l}0.9 \\
4\end{array}$ & 7 & $2.00 \%$ & $\begin{array}{l}0.72(-0.36 \\
, 1.80)\end{array}$ \\
\hline
\end{tabular}

\section{Results:}

The meta analysis done by the random effect models showed that out of eleven studies (table 1) that were analyzed, eight studies favor the use of essential oil mouthwash 9,11,14-19 in-comparison with only one study ${ }^{13}$ that favors the effect of chlorhexidine extract. Only two studies ${ }^{10,12}$ remain neutral agreeing to the null hypothesis that there is no difference in the effect of both the mouth washes (Fig. 1).

\section{Discussion:}

The prevention treatment of biofilm on the surface of the tooth has been a herculean task for dentists. The removal of the biofilm can be achieved both at the patient and at the professional level. At the patient level this process of removal is furthermore complicated by the complex dexterity required during mechanical tooth cleaning process ${ }^{20}$. The efficiency of cleaning is both time and technique bound. Hence in order to ease this process, mouth washes are frequently prescribed prophylactically by the dentist. Chlorhexidine has enjoyed being the dentist's favorite prescription for a greater period of time. The effectiveness of chlorhexidine has been well documented. The mechanism of action of chlorhexidine has 
been thoroughly researched with substantivity remaining undoubtedly the indisputable mechanism of action. Substantivity is defined as the ability of a substance to bind to tissue surfaces and be released over time, thus providing sustained antibacterial activity ${ }^{21}$. With the increase in the usage

antibiotic resistance is now emerging phenomena that has gained popularity and attention. Antibiotic resistance is a serious concern that is now challenging the prophylactic usage in practically all fields. Studies done by S. M. Clark et $\mathrm{al}^{22}$ and Carolyne Horner $\mathrm{et} \mathrm{al}^{23}$ have reported significant antibiotic resistance. It has also come to light that increased staining of teeth associated with long term chlorhexidine use is now a frequent patient aftermath complaint. Furthermore the usage has now been scrutinized with sufficient studies supporting the fact that prolonged chlorhexidine usage is directly proportional with levels of calculus formation. Studies done by Overholser et al, ${ }^{24} \mathrm{Grossman}$ et al, ${ }^{25}$ Charles $\mathrm{CH}$ et $\mathrm{al}^{10}$ have shown levels of calculus deposition and extrinsic tooth stain were significantly higher in the chlorhexidine group than in the essential oil mouth rinse group. Moreover the interaction of chlorhexidine with sodium lauryl sulfate, an active ingredient in dentifrice, is also now documented. Studies done by Barkvoll et $\mathrm{al}^{26}$ suggest that the activity of chlorhexidine is compromised with the long standing sodium lauryl sulfate containing dentifrice usage. Listerine though being the primary formed antiseptic was not used so frequently as in comparison with chlorhexidine. The effectiveness of Listerine was always comparatively lesser when compared to chlorhexidine in the yesteryears. This could be attributed to the fact that the trials were not done on a longitudinal basis $10,27,28$. Trials done in the year 1995 by Triratana $\mathrm{T}$ et $\mathrm{al}^{27}$ seems to be the fairly accepted trial for essential oils and formed the basis for in vivo studies. Newer studies done by Charles $\mathrm{CH}^{10}$ have now warranted the prolonged prophylactic usage of chlorhexidine. The present Meta analysis has included clinical trials that have been done for greater than three months.

\section{Recommendations:}

The debatable issue regarding the usage of chlorhexidine and essential oil mouthwashes can now be suggested based on the inference drawn from the present study that:

1. Prophylactic use of chlorhexidine should now be prescribed with caution. Their usage should be encouraged only for therapeutic purposes.

2. Further essential oil mouthwashes can be used for a prolonged interval for prophylactic regime.

3. Essential oil mouthwashes can be used to cater to the needs of the population that require extra care and dexterity that includes the handicapped, differently abled and geriatric population.

4. Longitudinal studies are now required to endorse the fact that chlorhexidine causes increased calculus formation and antibiotic resistance with special regard to oral cavity.

\section{Declarations}

The authors declare no competing interests. 


\section{References}

1. Fine D H Listerine: past, present and future--a test of thyme. J Dent. 2010 Jun;38 Suppl 1:S2-5.

2. Addy et al Chlorhexidine digluconate-an agent for chemical plaque control and prevention of gingival inflammation: J Periodont res 1986; 21(16):74-89.

3. Schroeder H E. Formation and Inhibition of Dental Calculus. Hans Huber, Berlin 1969; 145-1 Löe H, Von der Fehr FR, Schiött CR. Inhibition of experimental caries by plaque prevention. The effect of chlorhexidine mouthrinses Scand J Dent Res. 1972;80(1):1-9.

4. Hoffmann, T., Bruhn, G., Richter, S., Netuschil,L. \& Brecx, M. clinical controlled study on plaque and gingivitis reduction under long term use of low dose chlorhexidine solutions in a population exhibiting good oral hygiene. Clin Oral Investig 2001; 5: 89-95.

5. Silness J, Löe H. Periodontal disease in pregnancy II. Correlation between oral hygiene and periodontal condition. Acta odontologica scandinavica. 1964 Jan 1; 22(1):121-35.

6. Quigley GA, Hein JW. Comparative cleansing efficiency of manual and power brushing. The Journal of the American Dental Association. 1962 Jul 31; 65(1):26-9.

7. Turesky S, Gilmore ND, Glickman I. Reduced plaque formation by the chloromethyl analogue of victamine C. Journal of periodontology. 1970 Jan; 41(1):41-3.

8. Brecx M, Netuschil L, Reichert B, Schreil G. Efficacy of Listerine, Meridol and chlorhexidine mouthrinses on plaque, gingivitis and plaque bacteria vitality. Journal of Clinical Periodontology.1990;17(5):292-297.

9. Charles C, Mostler K, Bartels L, Mankodi S. Comparative antiplaque and antigingivits effectiveness of a chlorhexidine and an essential oil mouth rinse: 6-month clinical trial. J Clin Periodontol. 2004;31(10):878-84.

10. Claydon N., Manning, C. M., Darby-Dowman, A., Ridge, D., Smith, S. and Addy, M. The effect of polyvinyl pyrrolidone on the clinical activity of $0.09 \%$ and $0.2 \%$ chlorhexidine mouthrinses. Journal of Clinical Periodontology 2001; 28: 1037-1044.

11. Kouzmina, E., Yanuschevitch, O., Lapatina, A., Smirnova, T., \& Kuzmina, I. A Pilot Study Into the Effectiveness of Two Antimicrobial Mouthrinses in a Group of Russian Adults With Gingivitis. OHDMBSC 2010; 9(3):131-139.

12. Botelho M A, Bezerra Filho J G, Correa L L, Fonseca S G D C, Montenegro D, Gapski R, Heukelbach J. Effect of a novel essential oil mouthrinse without alcohol on gingivitis: a double-blinded randomized controlled trial. Journal of Applied Oral Science 2007;15(3):175-180.

13. Addy M, Moran J, Davies R M, Beak A, Lewis A. The effect of single morning and evening rinses of chlorhexidine on the development of tooth staining and plaque accumulation. Journal of clinical Periodontology 1982;9(2): 134-140.

14. Maruniak, J, W. B. Clark, C. B. Walker, I. Magnusson, R. G. Marks, M. Taylor, and B. Clouser. "The effect of 3 mouthrinses on plaque and gingivitis development." Journal of clinical Periodontology 1992; 19(1): 19-23. 
15. Sharma N, Charles C H, Lynch M C, Qaqish J, McGuire J A, Galustians J G, Kumar L D. Adjunctive benefit of an essential oil-containing mouthrinse in reducing plaque and gingivitis in patients who brush and floss regularly: a six-month study. The Journal of the American Dental Association 2004: 135(4), 496-504.

16. Shetty, Prashant R.; Setty, Swati B.; Kamat, Sushant S.; Aldarti, Ashok S.; Shetty, Shridhar N. Comparison of the antigingivitis and antiplaque efficacy of the herboral (herbal extract) mouthwash with chlorhexidine and listerine mouthwashes: a clinical study. Pakistan oral \& dental journal;apr203, vol. 33 issue 1, p76

17. Ramberg P, Furuich Y, Lindtie J, Gaffar A. A model for studying the effects of mouthrinses on de novo plaque formation. Journal of clinical Periodontology 1992; 19(7), 509-520.

18. Sekino, Satoshi, and Per Ramberg. "The effect of a mouth rinse containing phenolic compounds on plaque formation and developing gingivitis." Journal of clinical periodontology 32, no. 10 (2005): 1083-1088.

19. Diane Osso, Nehal Kanani. Antiseptic mouth rinses: an update on compartitive effectiveness risks and recommendations. Dental hygiene feb 2013 87:10-18.

20. Kozak KM, Gibb R, Dunavent J, White DJ. Efficacy of a high bioavailable cetylpyridinium chloride mouthrinse over a 24- hour period: a plaque imaging study. Am J Dent. 2005;18 Spec No:18A-23A.

21. S. M. Clark, A. Loeffler, and R. Bond Susceptibility in vitro of canine methicillin-resistant and susceptible staphylococcal isolates to fusidic acid, chlorhexidine and miconazole: opportunities for topical therapy of canine superficial pyodermaJ. Antimicrob. Chemother. (2015) 70 (7): 20482052 first published online March 5, 2015doi:10.1093/jac/dkv056.

22. Carolyne Horner, Damien Mawer, and Mark Wilcox.Reduced susceptibility to chlorhexidine in staphylococci: is it increasing and does it matter? J. Antimicrob. Chemother. first published online July 24, 2012 doi:10.1093/jac/dks284

23. Overholser CD, Meiller TF, DePaola LG, Minah GE, Niehaus C. Comparative effects of 2 chemotherapeutic mouthrinses on the development of supragingival dental plaque and gingivitis. $\mathrm{J}$ Clin Periodontol. 1990;17(8):575-79.

24. Grossman E, Meckel AH, Isaacs RL, Ferretti GA, Sturzenberger OP, et al. A clinical comparison of antibacterial mouthrinses: effects of chlorhexidine, phenolics, and sanguinarine on dental plaque and gingivitis. J Periodontol. 1989;60(8):435- 40.

25. Barkvoll P, Rolta G, Sevendsen K. Interation between chlorhexidine gloconate and sodim Lauryl Sulphate in vivo. J.Clinical Periodontol 1989 oct:16(9):593-5

26. Triratana T, Kraivaphan P, Amornchat C, Rustogi K, Petrone MP, Volpe AR. Effect of triclosan/copolymer pre-brush mouthrinse on established plaque formation and gingivitis: a sixmonth clinical study in Thailand. J Clin Dent. 1995;6(2):142-47

27. Bauroth K, Charles C, Mankodi S, Simmons K, Zhao Q, Kumar L. The efficacy of an essential oil antiseptic mouthrinse vs. dental floss in controlling interproximal gingivitis: a comparative study. $J$ Am Dent Assoc. 2003;134(3):359-65. 
28. Charles CH, Sharma NC, Galustians HJ, Qaqish J, McGuire JA, Vincent JW. Comparative efficacy of an antiseptic mouthrinse and an antiplaque/antigingivitis dentifrice. J Am Dent Assoc. 2001;132(5):670-75.

29. Sharma N, Charles C, Qaqish J, Galustians H, Zhao Q, Kumar L. Comparative effectiveness of an essential oil mouth rinse and dental floss in controlling interproximal gingivitis and plaque. Am $\mathrm{J}$ Dent. 2002;15(6):351-55

\section{Figures}

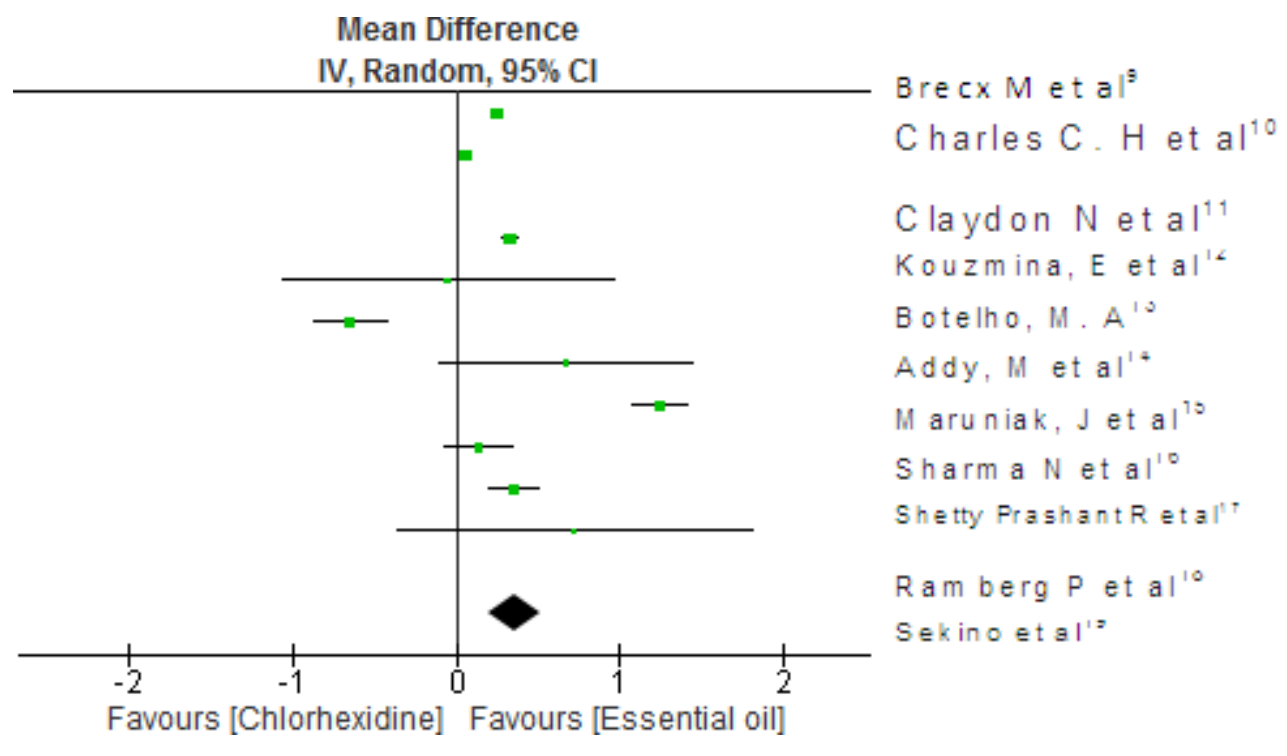

\section{Figure 1}

box forest plot used for the random effects model. 